\title{
A história de um passado "injusto": povos indígenas, livro didático e formação para cidadania
}

\author{
Mauro Cezar Coelho*
}

mauroccoelho@yahoo.com.br

\section{Taissa Cordeiro Bichara**}

taissabichara@gmail.com

\section{Resumo}

O trabalho propõe a reflexão sobre a relação entre ensino de História e formação para a Cidadania, a partir das narrativas sobre os povos indígenas nos livros didáticos de História para o Ensino Fundamental, aprovados pelo Programa Nacional do Livro Didático e utilizados no município de Belém, no estado do Pará. Argumentamos que a representação do Índio na narrativa didática possui determinada função pedagógica que inviabiliza o seu protagonismo nos eventos históricos.

\section{Palavras-chave}

Livro didático de História; Povos Indígenas; Ensino de História

The history of an "unfair" past: indigenous peoples, textbooks and education for citizenship

\begin{abstract}
The paper deals with the relationship between teaching History and citizenship shaping through the narratives about indigenous peoples in History textbooks of Primary Education, that were approved by the National Textbook Program and used in the city of Belém, in the State of Pará - Brazil. We argue that the pedagogical function attributed to the Indian figures in the didactic narrative directs the representation of which it is object, making impossible an approach that considers its protagonism in the narrative formulated by didactic literature in historical events.
\end{abstract}

\section{Keywords}

Textbooks; Indigenous Peoples; History Teaching 
A História, como disciplina escolar, esteve, desde o início, vinculada à formação para cidadania. Mesmo que tenhamos em conta as mudanças vividas pela disciplina -sejam aquelas decorrentes das alterações nas formas de produção do saber histórico (LE GOFF; NORA, 1997) ou dos currículos escolares (GALIAN, 2014) e as transformações nos sentidos atribuídos à cidadania (SANTOS, 1979), mantém-se uma relação de necessidade entre a História Ensinada e a Formação para a Cidadania.

Essa afinidade tem promovido reflexões que se ocupam com algumas de suas dimensões. Destacamos, aqui, à guisa de exemplo e sem qualquer pretensão em esgotar o volume de pesquisas sobre o tema, dois trabalhos. O primeiro, um estudo de Oldimar Cardoso, defende veementemente o vínculo entre o ensino de História e a formação para cidadania, além de destacar o período de redemocratização do Brasil como um contexto que evidencia o compromisso da disciplina com a formação do cidadão crítico (CARDOSO, 2007, p. 44). O segundo, de autoria de Diego Velasco e Vitor Barcellos (2014), trata dos sentidos atribuídos à cidadania na coleção didática «História e Vida», voltada para o ensino da História na Educação Básica, em duas versões: anos 1980 e 2010. Os autores notaram não apenas o vínculo estabelecido entre a disciplina e a formação para a cidadania, mas que o sentido atribuído a ela pelas coleções, em ambas as edições, é o de "cidadania política" - a cidadania é relacionada à conquista de direitos, embora a coleção de 2010 expanda o sentido incorporando a luta dos movimentos sociais comprometidos com a afirmação de identidades (p. 270).

Bem a propósito, desde o início do processo de Redemocratização, o lugar da História na Educação Básica vem sendo discutido e redimensionado em função das mudanças no contexto político nacional. Exemplares, nesse sentido, são as alterações curriculares com vistas ao redimensionamento da abordagem no trato com a História do Brasil. Conforme a legislação implementada na primeira década deste século, temáticas como a Cultura Afro-brasileira, a História da África e a História Indígena passam a compor o currículo escolar (COELHO; COELHO, 2013). Segundo Érika Frazão e Adriana Ralejo (2014, p. 176), as políticas educacionais elaboradas no referido contexto almejam o fortalecimento do processo democrático, pois encaminham a Inclusão e a Diversidade como parâmetros educacionais.

A Lei $n^{0} 11.645 / 2008$ compõe a política educacional em referência, pautando inclusive os editais do Programa Nacional do Livro Didático. Conforme aponta Maria de Fátima Barbosa da Silva (2012, p. 154), o edital do PNLD de 2011 evidencia grande preocupação com a formação para a cidadania, a não veiculação de estereótipos, e o respeito à diversidade. Diante disso, a reflexão de Edson Silva (2012, p. 219) chama a atenção para um movimento na abordagem sobre a formação nacional: ela não se pauta mais por uma concepção unitária, e sim plural. Além disso, o autor afirma que a identidade nacional - fundada pela ideologia da mestiçagem - pode ser problematizada por meio do reconhecimento e respeito à sociodiversidade.

As discussões acerca do Ensino de História e de sua relação com a formação para a cidadania compreendem, pois, questões diversas, as quais estão perpassadas por temas desde há muito vinculados ao saber histórico ensinado na Escola - a identidade, a formação nacional, a nacionalidade. Diante deles, pretendemos refletir sobre o modo como a categoria Índio é abordada em sete volumes de livros didáticos de História destinados aos Anos Finais do Ensino Fundamental, utilizados no município de Belém entre 1996 e 2014. Nosso objetivo é relacionar as abordagens presentes na literatura didática à função pedagógica da disciplina na Educação 
Básica $^{1}$, por meio da problematização do significado atribuído à formação para a cidadania nas mesmas coleções.

O aporte teórico que sustenta nossa reflexão é composto pelos conceitos de Discurso, proposto por Bakhtin (2008), e de Representação tal como concebido por Chartier (1990). Assim, partimos do pressuposto de que o livro didático é um bem cultural dotado de historicidade e inserido em contextos sociopolíticos específicos, de modo que detém um discurso portador de intencionalidades que revelam seus sentidos ao dialogar com o saber histórico escolar, a produção historiográfica e as políticas públicas pensadas para o Ensino de História na Educação Básica - os Parâmetros Curriculares Nacionais, os editais do Plano Nacional do Livro Didático e as Diretrizes Curriculares Nacionais para o Ensino Fundamental.

Consideramos, ainda, que, sendo a denominação Índio um termo genérico inventado e manuseado de diferentes formas ao longo do tempo, em conformidade com o momento histórico-político vivenciado, as representações evocadas nas obras didáticas podem revelar concepções e valores da realidade social, fornecendo, assim, uma identificação à categoria que nos interessa desvendar por meio da análise proposta. Além disso, tanto o discurso didático quanto as representações que ele formula acerca do Indígena facultam-nos a reflexão que pretendemos acerca da função pedagógica da disciplina na Educação Básica. Evidentemente que não entendemos a narrativa presente na literatura didática como o único ou o mais importante discurso escolar. Todavia, reconhecemos a sua relevância nos processos de conformação da história ensinada no cotidiano escolar e no fazer docente. Daí, então, a análise que oferecemos. Acompanhe-nos.

\section{As narrativas didáticas e a formação para cidadania}

Selecionamos sete coleções didáticas. Os critérios de seleção obedeceram à necessidade de configurarmos um corpo minimamente uniforme. Diante disso, adotamos dois critérios: a submissão ao Programa Nacional do Livro Didático e a consequente adoção por alguma escola do município de Belém, no Estado do Pará. Por meio deles, pretendemos verificar a eventual coerência entre as representações sobre o Índio e o discurso didático acerca do saber histórico em um mesmo sistema educacional.

Primeiramente, indicamos as coleções:

\begin{tabular}{|l|c|c|c|}
\hline \multicolumn{3}{|c|}{ COLEÇÕES ANALISADAS - ANOS FINAIS DO ENSINO FUNDAMENTAL } \\
\hline Título & Publicação & Editora & Edital \\
\hline História Temática & 2000 & Scipione & 2005 \\
\hline Projeto Araribá & 2007 & Moderna & 2008 \\
\hline Construindo consciências & 2008 & Scipione & 2011 \\
\hline Saber e fazer História & 2009 & Saraiva & 2011 \\
\hline Vontade de saber História & 2009 & FTD & 2011 \\
\hline Projeto Teláris & 2012 & Ática & 2014 \\
\hline História: sociedade e cidadania & 2012 & FTD & 2014 \\
\hline
\end{tabular}

Legenda: Livros didáticos analisados pelos autores. Text books analyzed by authors.

Fontes: autores.

\footnotetext{
${ }^{1}$ As categorias Índio e Indígena têm sido objeto de um sem-número de significações. Abordá-las ultrapassa os objetivos e as dimensões desse trabalho. Nós assumimos as categorias como referentes que buscam dar conta dos povos indígenas que, no caso em análise, comparecem nas narrativas didáticas relativas ao passado colonial. A bibliografia citada ao longo do artigo é pródiga em reflexões sobre o tema.
} 
A tabela indica a obra, o ano de publicação a editora e a indicação do ano em que foi avaliada pelo Programa Nacional do Livro Didático, por meio da indicação do edital a que se submeteu. Como se pode notar, as obras de que tratamos aqui foram publicadas ao longo de um período considerável. Elas guardam uma distância relativa, tanto no que se refere a sua produção quanto no que tange à sua avaliação pelo PNLD. Essa relativa distância no tempo nos pareceu profícua ao evidenciar mudanças ou permanências no modo pelo qual o Índio é representado e a história ensinada é concebida.

Ocupemo-nos das abordagens. Das sete coleções analisadas, seis organizam o conteúdo em sequência cronológico-linear e uma por meio de temáticas. A perspectiva eurocêntrica é soberana. Reina absoluta nas obras analisadas em sequência cronológica, mas é facilmente identificada na abordagem temática. A organização dos conteúdos tem, como se verá oportunamente, desdobramentos no que se refere à forma pela qual os povos indígenas são percebidos e à maneira como o saber histórico escolar se conforma.

Todas as coleções apresentam uma formulação acerca do saber histórico. Por meio dela, delimitam importância da disciplina na sociedade e quais são os agentes protagonistas dos eventos históricos.

Em História Temática, por exemplo, elucida-se que "Nossas histórias são diferentes umas das outras, porém não acontecem isoladamente. Estão ligadas ao grupo social a que pertencemos, ao lugar e ao tempo em que vivemos e ao nosso modo de vida [...]" (CABRINI; CATELLI; MONTELLATO, 2000, p. 22). A coleção encaminha a ideia da pluralidade, por meio da compreensão de que cada grupo social constrói a sua própria história em determinado espaço e tempo.
A narrativa orienta o entendimento de que o próprio leitor participa dos processos históricos ao utilizar pronome possessivo na primeira pessoa do plural.

Tais premissas são plenamente contempladas pelos Parâmetros Curriculares Nacionais de 1998. Perceber-se como agente capaz de intervir no cotidiano e reconhecer a diversidade sociocultural são condutas apontadas como fundamentais para o exercício da cidadania que inclui a "[...] cooperação e repúdio às injustiças, respeitando o outro e exigindo para si o mesmo respeito." (BRASIL, 1998). O documento também recomenda que as lutas dos movimentos sociais por direitos fazem parte do debate sobre a cidadania no país, de modo que o "respeito ao outro" por meio do reconhecimento da pluralidade caracteriza-se como um dos valores morais imprescindíveis para a referida formação.

Segundo as autoras Sonia Regina Miranda e Tania Regina de Luca, a avaliação dos livros didáticos, na qual as diretrizes são definidas nos editais do PNLD, é um dos caminhos possíveis para a compreensão da história que deve ser ensinada nos livros didáticos (2004, p.35). Os editais destacam os preceitos que as coleções devem seguir para que sejam aprovadas pelo Programa, de modo que o compromisso com a rejeição de preconceitos e a promoção do respeito mútuo são premissas tidas como vitais para o exercício da cidadania. Importa, então, ilustrar a referida configuração por meio de duas proposições descritas no edital de $2014^{2}$ :

7. promover positivamente a cultura afrobrasileira e dos povos indígenas brasileiros, dando visibilidade aos seus valores, tradições, organizações e saberes sociocientíficos, considerando seus direitos e sua participação em diferentes processos históricos que marcaram a construção do Brasil, valorizando as diferenças culturais em nossa sociedade multicultural;

${ }^{2}$ Os fundamentos de respeito e combate ao preconceito, necessários à formação para cidadania e demonstrados no PNLD 2014, também podem ser encontrados nos editais de 2008 e 2011. 
8. abordar a temática das relações étnico -raciais, do preconceito, da discriminação racial e da violência correlata, visando à construção de uma sociedade antirracista, solidária, justa e igualitária (BRASIL, 2014, p.54).

Nota-se a preocupação com a temática étnicoracial, no sentido de que as obras devem evitar representações depreciativas, além de exaltar as tradições e a diversidade cultural. Essa conformação está presente, ainda, nas Diretrizes Curriculares para o Ensino Fundamental de nove anos. De fato, elas relacionam ensino, cidadania e formação de valores morais ao considerar que:

Mais ainda: o conhecimento de valores, crenças, modos de vida de grupos sobre os quais os currículos se calaram durante uma centena de anos sob o manto da igualdade formal, propicia desenvolver empatia e respeito pelo outro, pelo que é diferente de nós, pelos alunos na sua diversidade étnica, regional, social, individual e grupal, e leva a conhecer as razões dos conflitos que se escondem por trás dos preconceitos e discriminações que alimentam as desigualdades sociais, étnico-raciais, de gênero e diversidade sexual, das pessoas com deficiência e outras, assim como os processos de dominação que têm, historicamente, reservado a poucos o direto de aprender, que é de todos. (BRASIL, 2013, p. 115).

Assim, na resolução, permanece a noção do "respeito ao outro" como conduta necessária ao exercício da cidadania, mas amplia-se a discussão para o direito à diferença. Isto é, no processo de aprendizagem, o estudante do Ensino Fundamental deve entender como as diferenças entre os grupos sociais foram construídas historicamente, como tais diferenças demarcaram ações e como estas impactam as relações sociais.

Tendo em vista a ênfase dada pelos referidos documentos à compreensão dos diferentes grupos que formam a sociedade, as narrativas didáticas incorporam essas proposições e expõem ser objetivo principal da
História o conhecimento do passado para entendimento do tempo presente. Isso pode ser plenamente percebido no desenvolvimento do primeiro capítulo do volume destinado ao sexto ano da coleção Projeto Teláris:

Existem muitas razões para se estudar História. Uma das mais relevantes talvez seja o fato de que todos nós, independentemente de onde nascemos ou de nossa condição, temos necessidade de conhecer nosso passado. [...] Essas informações, além de ampliar nossos horizontes, nos levam a conhecer outras culturas, diferentes grupos humanos e modos de viver $e$ pensar. E, quando tomamos consciência de que o mundo é feito por grupos com experiências diferentes, aprendemos. Por exemplo, que não existem povos ou religióes melhores ou piores do que outros. Todos os povos fazem parte da história da humanidade e merecem o mesmo respeito com que queremos e gostamos de ser tratados. (COLEÇÃO PROJETO TELÁRIS, $6^{\circ}$ ano, p. 12-14).

Atribui-se, então, à disciplina a responsabilidade por evidenciar as relações estabelecidas entre os diferentes sujeitos ao longo do tempo, com o objetivo de promover o reconhecimento e o respeito aos grupos sociais que integram a sociedade brasileira - ambos valores entendidos como primordiais na formação para a cidadania. Essa seria, portanto, a função pedagógica e moral da História na narrativa didática. Vejamos como isso se desdobra nos livros didáticos analisados.

\section{O Indígena e a função pedagógica do Saber Histórico Escolar}

$\mathrm{Na}$ análise que realizamos, notamos uma diferença entre os livros que adotam uma organização dos assuntos por temáticas e os que os ordenam em uma sequência cronológico/temporal. Diante disso, trataremos, inicialmente, desse último conjunto de livros, os quais compreendem a maior parte do corpo documental 
A HISTÓRIA DE UM PASSADO "INJUSTO": POVOS INDÍGENAS, LIVRO DIDÁTICO E FORMAÇÃO PARA CIDADANIA

trabalhado (seis coleções). Nele, identificamos três abordagens da temática indígena. Apresentamo-las não por ordem de importância, mas considerando a relação de necessidade que há entre elas. Assim, iniciaremos pelo que denominamos de Introdução ao Estudo dos Povos Indígenas, a seguir trataremos da Relação dos Povos Indígenas com os demais agentes históricos e, por fim, da Condição dos Povos Indígenas nos processos históricos.

Denominamos de Introdução ao Estudo dos Povos Indígenas um movimento comum às coleções - introduzir os leitores na temática indígena. Esse movimento apresenta os prolegômenos da temática, situando as características "gerais" ou "comuns" dos povos indígenas. $\mathrm{O}$ excerto seguinte é ilustrativo:

Esses povos apresentavam diferenças entre si, e cada um deles tinha seu próprio modo de vida, sua língua, seus costumes e suas crenças. [...] Alguns costumes das sociedades não indígenas foram incorporadas, pelos caiapós. Atualmente, por exemplo, eles jogam futebol e assistem à televisão. [...] Os povos indígenas que vivem no Brasil atualmente, em sua maioria, mantém contato com a sociedade não indígena. Apesar disso, eles preservam vários costumes de seus antepassados. (COLEÇÃO VONTADE DE SABER, $7^{\circ}$ ano, p. 82-83).

Tal como no excerto em destaque, são comuns enfoques desse tipo, nos quais os povos indígenas são apresentados a partir de características que lhes são comuns. Essas, via de regra, dizem respeito a costumes e índices culturais (crenças, língua, habitação e vida material, entre outros). Note-se, porém, que, ainda que se faça menção às mudanças experimentadas pelos indígenas no trato com as sociedades não-indígenas, a preocupação é com a definição dos costumes e da cultura tidos como genuinamente indígenas. Nesse sentido, são frequentes as perspectivas que assumem aspectos culturais das sociedades indígenas como livres de processos de ressignificação, como se eles fossem exatamente os mesmos desde os primórdios da organização social daqueles povos, conforme fica claro na ressalva ao final do excerto: "eles preservam costumes de seus antepassados".

Os povos indígenas, pois, são frequentemente apresentados como infensos a mudanças. Isso não quer dizer que os livros didáticos não reconheçam as transformações experimentadas por eles. Porém, verificamos que, em relação aos indígenas, os livros didáticos privilegiam a permanência em detrimento da mudança. $\mathrm{O}$ mesmo excerto é elucidativo dessa característica comum às obras. Ao reportarem a apropriação de costumes não indígenas pelos Kayapó, os autores não abordam a questão historicamente. Significativo, nesse sentido, é o uso da categoria incorporação e não apropriação - pois, enquanto a primeira categoria encaminha o sentido de anexação, inclusão e integração, a segunda significa tornar próprio e, no caso em questão, promover alterações de modo a tornar seus aqueles aspectos da cultura apropriados do outro (GORDON, 2006).

Depreende-se, assim, que, mesmo nos capítulos dedicados exclusivamente à diversidade étnica, o Índio é retratado não apenas como isento de história, mas também como um sujeito passivo. A narrativa não se debruça sobre as ações indígenas e sobre o modo como ele interfere no curso dos eventos. Essa dimensão da abordagem introdutória acerca dos povos indígenas pode ser percebida em exemplo extraído de outra coleção:

Organizada em diversos povos, com culturas e línguas diferentes, a população indígena não utilizava nenhuma forma de dinheiro nem acumulava riquezas. Os povos indigenas consideravam a terra um bem comum. Os portugueses, ao contrário, desejavam explorar riquezas e ser donos das terras que encontrassem. [...] Muitos dos atuais povos descendem de 
grupos desestruturados durante o periodo colonial. E a razão dessa desestruturação foi a forma como os recémchegados europeus impuseram, desde 1500, a conquista e a ocupação das terras. (COLEÇÃO CONSTRUINDO CONSCIÊNCIAS, 6 a série, p. 82).

Conforme o excerto deixa claro, a vida indígena anterior à chegada dos europeus era livre de mudanças. Essas últimas, aliás, são percebidas como atributos europeus - dinheiro, riqueza, acumulação - os quais impuseram alterações na vida dos povos indígenas. A abordagem é ambígua, pois ainda que os livros didáticos dispensem atenção aos grupos indígenas, reservando unidades e capítulos, os povos indígenas permanecem sendo representados por dois atributos: ingenuidade e vitimização (COELHO, 2007).

Esse aspecto da abordagem relativa à introdução ao estudo dos povos indígenas nos livros didáticos é reiterada e constitui o modo pelo qual os indígenas são, frequentemente, percebidos: personagens passivos dos processos históricos no qual estão inseridos. Na narrativa desenvolvida no excerto a seguir, considera-se que:

As terras que formariam o território brasileiro pertenciam aos indigenas. Embora eles não tivessem a noção de propriedade que temos ("isso é meu" "aquilo é seu"), essas terras eram o lar deles, o lugar onde nasceram e a fonte de sua existência. [...] "Vamos ver também como incapacidade dos colonizadores de respeitar a cultura dos nativos da América, suas tradições, crenças e modos de vida, contribui para um dos maiores genocídios da história, responsável pelo extermínio de milhões de indígenas. (COLEÇÃO PROJETO TELÁRIS, $7^{\circ}$ ano, p. 132-133).

Notem o esvaziamento da significação histórica da relação de alteridade na Idade Moderna. Não se trata de situar o contexto a partir do qual se constituíram os modos como os europeus percebiam o Outro, mas de utilizar tal percepção para fins pedagógicos. Ao utilizar a expressão "incapacidade de respeitar a cultura" para se referir às primeiras relações entre os europeus e os povos indígenas, logo após frisar sobre o fato do território que corresponde ao Brasil atual ter sido "o lar dos indígenas", a narrativa evoca a noção de injustiça, isto é, a colonização significou a expropriação e dizimação de várias etnias.

Ressaltamos que não é nossa intenção negar ou minimizar a violência do processo. No entanto, reconhecemos que os processos nos quais os povos indígenas tomaram parte, ao longo do período que denominamos de Colonização Portuguesa, não se resumiram ao extermínio e à passividade diante dos eventos. Como aponta uma extensa bibliografia relativa ao período, os povos indígenas não se limitaram à condição de coadjuvantes. Ao contrário, pautaram muitas de suas ações em função de interesses, agendas e projetos (MONTEIRO, 1994; VAINFAS, 1995; CARVALHO JÚNIOR, 2005; GARCIA, 2007; ROLLER, 2013).

O modo pelo qual os povos indígenas são percebidos na relação com os demais agentes nos leva à consideração da segunda abordagem a que nos referimos, a Relação dos Povos Indígenas com os demais agentes históricos. Por meio dela, privilegiamos o trato dispensado pela literatura didática ao contato entre missionários e bandeirantes paulistas. Os livros didáticos analisados não se ocupam com a coexistência de povos indígenas e africanos ou negros escravizados. Isso pode-se dever à tese da "substituição da mão de obra indígena pela africana", a qual pressupõe certo distanciamento entre tais agentes, como se elas não tivessem ocorrido. Daí nossa opção por tratar da relação entre dois agentes que, para além da literatura didática, tem sido extensivamente analisados pela produção historiográfica.

Os aldeamentos missionários, nos quais religiosos de diversas ordens reuniam indígenas, os quais 
A HISTÓRIA DE UM PASSADO "INJUSTO": POVOS INDÍGENAS, LIVRO DIDÁTICO E FORMAÇÃO PARA CIDADANIA

eram submetidos aos ensinamentos cristãos, são recorrentemente tratados pelos livros analisados. O excerto a seguir é um exemplo do modo pelo qual as Missões são percebidas:

No final do século XVII, jesuitas espanhóis fundaram, ao longo dos rios Uruguai e Paraguai, mais de cinquenta missões, das quais sete missões, das quais sete estavam localizadas no território do atual Brasil. Nelas os padres disciplinavam os indigenas por meio do trabalho agrícola e da catequese. (COLEÇÃO PROJETO ARARIBÁ, $8^{\circ}$ ano, p. 11).

Se no trato com os momentos iniciais da presença europeia na América, as narrativas asseveram a ausência de ambição dos indígenas e, consequentemente, seu pouco apreço pelo trabalho sistemático, as missões surgem nas narrativas como espaços de disciplinarização dos índios. Elas transformariam os povos indígenas em mão de obra para o alcance dos "objetivos exploratórios" da colonização. Notem que, segundo essa perspectiva, os indígenas não promoveram mudanças. É como se a intervenção nos eventos estivesse fora de sua competência. Mas, a narrativa encaminha a compreensão de que eles sofrem mudanças - promovidas por outrem.

$\mathrm{O}$ trato com as Missões estabelece que a presença europeia submeteu os povos indígenas a opções que, ao final e ao cabo, levavam ao mesmo resultado: por um lado, a dizimação - como demonstrado na abordagem que tratamos inicialmente -por outro, a submissão por meio da conversão à fé católica. Ambas as opções significavam o extermínio de seus modos de vida.

Esse padrão na abordagem do trato entre indígenas e não indígenas pode ser percebido na forma como a narrativa didática situa a atuação dos bandeirantes, ainda na coleção Projeto Araribá:
Os bandeirantes também procuravam capturar indios nas missões, aldeamentos organizados pelos padres jesuitas desde fins do século XVI, pelo fato de esses índios já estarem em contato com o branco e submetido à disciplina do trabalho nos moldes europeus.[...] Os exploradores paulistas garantiram sua sobrevivência colocando em prática conhecimentos indigenas. Aprenderam com os indios a caminhar pelas matas guiando-se pelos astros e rastros de animais, a marcar caminhos dobrando galhos e golpeando troncos de árvores, a reconhecer a aproximação de cobras, onças e outros perigos. A experiência dos nativos na observação da natureza também foi usada para localizar água potável e aproveitar o líquido extraído de plantas suculentas, como o umbuzeiro e diversas espécies de cipós. (COLEÇÃO PROJETO ARARIBÁ, $8^{\circ}$ ano, p. 16-17).

Nesse caso, além do recurso à noção de submissão ("submetido à disciplina do trabalho"), o texto considera que os indígenas aldeados estavam plenamente incorporados aos "moldes europeus". Mais uma vez, verificamos a postura que assume o Índio como objeto da mudança, nunca o agente. Não por acaso, o Índio atua como auxiliar dos exploradores paulistas, que são os personagens protagonistas do processo de colonização na condição de protagonistas.

Conforme a narrativa apresentada pelas obras didáticas organizadas em sequência cronológica, aos povos indígenas não restaram alternativas outras que não a submissão ou o desaparecimento. Segundo tal encaminhamento, independentemente do agente com o qual travaram algum tipo de interação, o resultado foi sempre o mesmo: violência (física ou simbólica) ou o extermínio físico. Em análise anterior, Mauro Cezar Coelho argumentou que tal perspectiva servia à compreensão (equivocada, porém, recorrente) do conteúdo da formação para a cidadania: a denúncia da exploração e das violências objetivava a conscientização dos alunos sobre as injustiças sociais, com vistas à capacitação 
do cidadão participativo e comprometido com a construção de um mundo melhor (COELHO, 2009).

Neste trabalho, aprofundamos a discussão. Consideramos que tal função didática permanece presente nas obras publicadas no espectro temporal abordado aqui. Todavia, a função didática não se limita a essa dimensão do lugar da História na Educação Básica. Por vias tortas, menos que encaminhar o estudante nas formas de compreensão histórica, a perspectiva de que tratamos aqui reitera uma tradição formulada no século XIX e, com isso, remete a História Ensinada à transmissão de uma tradição acumulada, sem qualquer crítica a seu caráter excludente e incompatível com os avanços que a produção historiográfica conheceu no último século.

Vejamos, nesse sentido, o excerto seguinte:

Não foram apenas os tupis que conheceram e combateram os europeus que invadiam seus domínios, desde 1500 até hoje, muitos outros povos indígenas também foram mortos ou expulsos de suas terras, tomadas por fazendas, mineradoras $e$ outras formas de ocupação que os brancos praticaram ao longo dos séculos para explorar os recursos da natureza. (COLEÇÃO SABER E FAZER HISTÓRIA, $7^{\circ}$ ano, p. 51)

Conforme apontamos páginas atrás, a preocupação é demarcar a ausência de mudança na trajetória dos povos indígenas. Como se vê no excerto, a exploração de recursos é apontada como o principal objetivo dos portugueses na colonização e, por extensão, do homem branco desde então. Aos índios resta a luta perene contra os exploradores. No entanto, a luta não é dimensionada no tempo, apontando a sua situação histórica e a diversidade que ela abriga, se considerarmos indígenas ou brancos. No afã de destacar a desapropriação das terras e o extermínio dos povos indígenas, a narrativa didática retira dos povos indígenas a competência de atuar historicamente. Eles não conhecem mudança, não viveram vitórias, não conformaram agendas e não protagonizaram eventos. No mesmo excerto, vale destacar, o combate empreendido pelos tupis é interpretado como uma reação às investidas colonizadoras, de modo que o europeu continua sendo o protagonista. $\mathrm{Na}$ narrativa didática, a relação entre indígenas e os demais agentes obedece a um único roteiro: extinção ou aculturação por meio da conversão, como bem observado por Maria Regina Celestino de Almeida (2009, p. 27).

Chegamos, finalmente, à abordagem que denominamos de Condição dos Povos Indígenas nos processos históricos. Sob essa categorização, reunimos as referências aos indígenas, presentes nas narrativas didáticas, no trato com processos históricos incluídos na história contada pelos livros didáticos. Percebemos que, nesses casos, o indígena aparece como um auxiliar do colonizador. Ainda que as narrativas didáticas registrem a ação indígena, ela sempre está a serviço do colonizador.

Elucidativo, neste sentido, é o modo pelo qual é percebida a participação indígena na dinâmica da escravidão, em Saber e Fazer História: "A partir da conquista europeia, os nativos armados pelos portugueses começaram a escravizar indígenas de outras tribos e a fornecê-los para os colonos" (COTRIM; RODRIGUES, 2009, p. 110). Em primeiro lugar, é importante destacar que o excerto é acompanhado de uma breve consideração sobre os interesses próprios dos povos indígenas, já que se serviam de armamentos do colonizador para combater os povos considerados seus inimigos tradicionais. No entanto, o excerto deixa clara a perspectiva da qual se parte: o fato motivador é a conquista europeia; a escravização tem início e sentido, a partir dos interesses europeus; e, por fim, as relações entre os povos indígenas são percebidas como dependentes da interação com 
A HISTÓRIA DE UM PASSADO "INJUSTO": POVOS INDÍGENAS, LIVRO DIDÁTICO E FORMAÇÃO PARA CIDADANIA

os europeus, conforme pode ser percebido, também, em outro excerto:

No contato entre os povos tupis e os portugueses ocorreu tanto o relacionamento amistoso quanto a guerra. As relações amigáveis se davam por meio: a) do escambo (troca) de pau-brasil, uma madeira abundante no litoral brasileiro, por objetos úteis aos indígenas, como machados, pás, foices, facas, espelhos;

b) do casamento de portugueses com mulheres tupis;

c) da alianças com alguns grupos indigenas para guerrear contra outros, os portugueses aliaram-se aos Tupiniquim para guerrear contra os Tupinambá, fazê-los prisioneiros e escravizá-los. (COLEÇÃO HISTÓRIA: sociedade e cidadania, $7^{\circ}$ ano, p. 232)

Os pontos destacados pela passagem referida encaminham o entendimento de que os povos indígenas tinham ação relevante em alguns aspectos do "contato", como o casamento e as alianças. Não obstante, eles não atingem a condição de agente histórico, eles não são vistos como agentes que interferem no curso da História, pois é o europeu quem explora, catequiza e povoa.

A primazia da representação do Índio submisso nas narrativas didáticas constrói ainda a ideia de vítima, justamente por conta dos valores morais relacionados à rejeição das injustiças sociais e do reconhecimento da diversidade sociocultural. Em Saber e Fazer História, os autores asseveram que:

Os povos indígenas do Brasil não querem ser reconhecidos apenas pelo que aconteceu no passado. Eles querem melhorar sua condição de vida no presente. Por isso reivindicam, entre outras coisas, a definição dos limites de suas terras e o direito de explorá-las, além da aprovação de leis que garantam outros direitos. (COLEÇÃO SABER E FAZER HISTÓRIA, $7^{\circ}$ ano, p. 44).
Como já mencionamos, as diretrizes curriculares nacionais para o Ensino Fundamental de nove anos consideram o aprendizado sobre as lutas dos movimentos sociais como parte da formação para cidadania (BRASIL, 2013, p. 105). Se considerarmos o excerto em destaque no conjunto de referências aos povos indígenas, fica claro o quanto a representação feita sobre o Índio está relacionada à compreensão do que significa formar para a cidadania: formar no aluno/leitor da narrativa didática uma sensibilidade para com a "causa" indígena.

O excerto que selecionamos a seguir é elucidativo, neste sentido:

\begin{abstract}
Hoje, mais de 500 anos após a conquista europeia das terras americanas, a humanidade começa a avaliar sua dívida para com os indígenas da América. As principais plantas de que a humanidade se alimenta foram descobertas e domesticadas pelos ameríndios. (COLEÇÃO HISTÓRIA: sociedade e cidadania, $7^{\circ}$ ano, $\mathrm{p}$. 234).
\end{abstract}

O uso da categoria "dívida" evidencia o sentido da representação que é construída sobre o Índio. Com vistas à consecução da oferta de uma formação cidadã, a exposição das violências sofridas pelos povos indígenas tem menos o objetivo de entender os processos nos quais essas mesmas violências foram algumas das variáveis na teia de relações mantidas entre os agentes históricos do que a promoção do respeito às etnias enquanto conduta moral necessária ao exercício da cidadania.

A representação do Índio encaminhada pela única coleção a organizar o conteúdo por meio de temas segue o mesmo princípio. A coleção elege temáticas diferentes para cada um dos volumes - tempos e culturas, terra e propriedade e cidadania são algumas delas. Segundo essa perspectiva os eventos históricos são acionados em função do tema em discussão. No que diz 
respeito à abordagem relativa ao indígena, verificamos uma mudança significativa em relação às demais coleções organizadas em sequência cronológico-temporal: na coleção temática ele comparece no tratamento das diversas temáticas, de modo que a presença indígena não se limita ao passado colonial, como é frequente nas demais coleções.

Essa postura, no entanto, não resulta em representação distinta da já mencionada. Em primeiro lugar, porque a abordagem temática acaba por recorrer aos povos indígenas (e aos demais agentes) como elementos ilustrativos do tema abordado. É o que observamos, por exemplo, em um tópico acerca de Autobiografias:

Um jovem índio do parque Xingu contou sua história quando estudava numa escola local. Juntamente com outros trabalhos, ela foi recolhida por professores dessa e de outras escolas indigenas num livro publicado pelo Ministério da Educação. (COLEÇÃO HISTÓRIA TEMÁTICA, $5^{\text {a }}$ série, p. 17).

A situação histórica do "jovem índio", o lugar das histórias de vida na cultura de que participa, a condição política de textos dessa natureza, tendo em vista o que são as Escolas Indígenas - nada disso é problematizado no texto. A formulação do jovem índio é equiparada à dos demais agentes acionados, esvaziando o sentido da perspectiva histórica. Isso fica ainda mais evidente no capítulo intitulado «Mesma época, diferentes tempos», no qual as sociedades indígenas são incluídas em um rol de culturas, como a dos nova iorquinos e dos inuits do Pólo Norte para demonstrar os diferentes modos de vida numa mesma temporalidade:

Segundo dados do Instituto Socioambiental, existiam cerca de 270 mil indios em 1995 no Brasil, distribuídos em 128 reservas. Em uma delas, o Parque Nacional do Xingu, que abriga aproxi- madamente 4 mil indios e 18 tribos, pratica-se um ritual funerário conhecido como Quarup, palavra que significa "tronco de árvore". Nessa festa, que reúne tribos todas as tribos da região, os indios enfeitam troncos de árvores em homenagem aos mortos do ano. Dançam, lutam e, ao amanhecer, jogam os troncos no rio a fim de libertar as almas. Dessa forma, revivem a sua lenda de criação do mundo. (COLEÇÃO HISTÓRIA TEMÁTICA, $5^{\mathrm{a}}$ série, p. 57).

O indígena, como os demais agentes, aparece na condição de exemplo e ilustração dos temas centrais de cada capítulo. A ausência de perspectiva histórica, por meio da qual o estudo dos processos históricos está remetido ao domínio de categorias e conceitos próprios da disciplina, acentua, então uma compreensão do indígena como um suporte para tratar de questões selecionadas pelos autores. Não obstante, o conteúdo da representação acerca do Índio é a mesma que nas coleções organizadas por sequência cronológico-temporal. Vejamos o excerto seguinte:

A maioria das nações indígenas, ao entrar em contato com os não-índios, sofreu massacres, contaminação por doenças, perseguições. O povo Bororo, por exemplo, que, segundo levantamento, em 1994 contava somente com 914 integrantes, no início do século, tinha uma população que pode ter atingido até $10 \mathrm{mil}$ indivíduos, distribuidos em mais de 30 aldeias. Séculos antes, os Bororo foram violentamente perseguidos pelos primeiros colonizadores do Brasil. Outro povo indigena que tem sofrido sérias perdas no contato com os não-índios são os Yanomami. Em 1817, por exemplo, ocorreu o massacre de Haximu, que se deu quando teve início uma grande corrida ao ouro em Roraima. Vários indígenas foram assassinados por garimpeiros, e suas terras, invadidas. Ainda hoje continuam as disputas em torno da demarcação das terras Yanomami. (COLEÇÃO HISTÓRIA TEMÁTICA, $5^{\mathrm{a}}$ série, p. 25) 
Conforme o excerto, o contato com os "não índios" é sinônimo de desvantagem para as sociedades indígenas. Considere-se que a narrativa destaca a passividade indígena perante a colonização, reforçando uma visão polarizada sobre índios e não índios - passivos/ agentes, vítimas/algozes, coadjuvantes/protagonistas.

Tal postura diante dos povos indígenas vem sendo abandonada por parte da produção historiográfica, a partir da conformação de um campo de pesquisas que assume uma outra perspectiva: considerar a agenda indígena na análise de processos históricos.O objetivo político, subjacente a essa perspectiva, é, de um lado, garantir o estatuto de agente histórico pleno aos povos indígenas e, de outro, desvincular as análises dos interesses políticos da hora. De acordo com Maria Hilda Paraíso (1994, p. 180), desde o período colonial, as imagens veiculadas sobre os indígenas corresponderam aos interesses de momento. Manuela Carneiro da $\mathrm{Cu}-$ nha (1992, p. 17) desenvolveu uma crítica à historiografia brasileira, apontando o alinhamento da produção historiográfica aos processos de eliminação física e étnica dos povos indígenas, ao assumir que os índios foram vítimas indefesas do sistema mundial - o processo colonizador.

O campo da História Indígena atua no sentido de desconstruir as imagens atribuídas aos povos indígenas, tais como as que os livros didáticos analisados divulgam. É o caso do trabalho de Nádia Farage (1991, p. 86) acerca da política portuguesa para a região do Rio Branco, no qual a perspectiva indígena é ressaltada, não apenas no trato com os europeus, mas nas relações travadas entre os grupos indígenas. Do mesmo modo, Maria Regina Celestino de Almeida (2003, p. 147) redimensionou o espaço das aldeias enquanto local de rearticulação e recriação dos povos indígenas. Ainda sobre as aldeias missionárias, Almir Diniz (2015, p. 77) afirmou que, ao viver nas missões, os indígenas aprendiam ofícios - artesãos, carpinteiros - e usavam essas habilidades segundo seus próprios interesses.

Enfim, as produções sobre História Indígena desconstroem as formulações que desenham a figura do Índio ingênuo e passivo diante do Outro, que não se reinventa e não vivencia mudanças. A questão que emerge, então, diz respeito ao descompasso da literatura didática frente ao que vem produzindo a historiografia especializada. À primeira vista, poder-se-ia argumentar que se trata do lapso possível, entre o tempo da produção historiográfica e o tempo da produção didática. O campo da história indígena, todavia, vem-se conformando desde a década de 1970, de modo que os tempos de produção não podem servir de justificativa para o descompasso.

Argumentamos aqui que o apego da literatura didática a uma representação denunciada e criticada pela historiografia especializada se deve menos ao desconhecimento e mais à função pedagógica assumida por aquela literatura para o saber histórico-escolar e, nele, ao lugar ocupado pela figura do indígena. Concebida e organizada segundo a tradição quadripartite e demarcada pela perspectiva eurocêntrica, a literatura didática permanece vinculada à concepção de História do século XIX e a sua função pedagógica: formar o cidadão, por meio da sua inserção em uma dada tradição, assumida como sua herança, e da divulgação e formação de valores tidos como necessários à vida em sociedade.

Os povos indígenas constituem, diante disso, um dilema de difícil enfrentamento. No que concerne à formação axiológica, os povos indígenas cumprem a função pedagógica de despertar compaixão no trato com o Outro. Para tanto, a narrativa didática deforma a imagem do Índio, adequando-a aos propósitos da função pedagógica - vítima, ingênuo, incapaz, imaculado, herói. Ao fazê-lo, porém, ao invés de se distanciar da 
visão construída sobre os povos indígenas no século XIX, a narrativa didática reproduz o veredito de que os povos indígenas não possuem história - estão presos fora do tempo, não vivem mudanças, não interagem com os demais agentes a partir de interesses próprios, não protagonizam.

As narrativas didáticas afirmam que os povos indígenas não são todos iguais, que lutaram e continuam lutando por direitos, que, no passado colonial, fugiam, rebelavam-se e formavam alianças. Tais ações, todavia, são entendidas como reações diante da ação europeia - o protagonismo permanece atributo exclusivo do europeu e do branco. São eles que escravizam, exploram, povoam, catequizam segundo seus interesses. É essa a tradição que se quer ver reproduzida e se pretende ver incorporada pelos cidadãos brasileiros ao longo de sua trajetória escolar. Essa é a função pedagógica, então, atribuída ao saber histórico - transmitir uma tradição, legar uma herança e, por conseguinte, obliterar outras.
Deformam-se, nesse movimento, não apenas os objetivos da História Ensinada, na Educação Básica, mas os sentidos da formação para a cidadania e a contribuição que o saber histórico pode proporcionar.

O presente estudo demonstra ainda a importância do fomento às pesquisas em ensino de História na região Norte, pois, de acordo com Wilma Baía Coelho e Mauro Cezar Coelho (2010, p. 119), nas práticas em sala de aula, o livro didático é a principal fonte de informação das renovações historiográficas para o professor da Educação Básica. Por conta disso, precisa superar o "estatuto de informação" (COELHO; COELHO, 2012, p. 150) e engendrar as noções de construção histórica e fluidez das relações sociais, de modo que os sujeitos históricos possam ser percebidos sem lugares pré-determinados, assim como os processos históricos entendidos como fruto das aspirações humanas, distanciando-se de uma perspectiva que limita o potencial da História ensinada.

\section{Fontes}

APOLINÁRIO, Maria Raquel (Org.). Projeto Araribá. Editora Moderna: São Paulo, 2007. AZEVEDO, Gislaine Campos; SERIACOP, Reinaldo. Projeto Teláris. Editora Ática: São Paulo, 2012. BOULOS JR, Alfredo. História: sociedade \& cidadania. Editora FTD: São Paulo, 2012.

BRASIL. SECRETARIA DE EDUCAÇÃO FUNDAMENTAL. Parâmetros curriculares nacionais: terceiro e quarto ciclos: apresentação dos temas transversais. Brasília: MEC/SEF, 1998. Disponível em: <http:// portal.mec.gov.br/seb/arquivos/pdf/ttransversais.pdf>. Acesso em: 06 jun. 2017.

BRASIL. MINISTÉRIO DA EDUCAÇÃO. Diretrizes Curriculares Nacionais para o Ensino Fundamental de 9 (nove) anos. In: Diretrizes Curriculares Nacionais da Educação Básica. Brasília, 2013. Disponível em: <http:// portal.mec.gov.br/index.php?option=com_docman\&view=download\&alias=15548-d-c-n-educacao-basica-novapdf\&Itemid=30192>. Acesso em: 06 jun. 2017.

BRASIL. MINISTÉRIO DA EDUCAÇÃO. EDITAL DE CONVOCAÇÃO PARA O PROCESSO DE INSCRIÇÃO E AVALIAÇÃO DE COLEÇÕES DIDÁTICAS PARA O PROGRAMA NACIONAL DO LIVRO DIDÁTICO - PNLD 2014. Brasília. Disponível em: <http://www.fnde.gov.br/programas/livro-didatico/livro-didatico-editais>. Acesso em: 06 jun. 2017.

CABRINI, Conceição; CATELLI, Roberto; MONTELLATO, Andrea. História Temática. Editora Scipione: São Paulo, 2005.

COSTA, Luís César; ITAUSSU, Leonel. Construindo Consciências. Editora Scipione: São Paulo, 2008. COTRIM, Gilberto; RODRIGUES, Jaime. Saber e fazer História. Editora Saraiva: São Paulo, 2009. 
A HISTÓRIA DE UM PASSADO "INJUSTO": POVOS INDÍGENAS, LIVRO DIDÁTICO E FORMAÇÃO PARA CIDADANIA

DIAS, Adriana Machado; GINBERG, Keila; PELLEGRINI, Marco César. Vontade de Saber História. Editora FTD: São Paulo, 2009.

\section{Referências}

ALMEIDA, Maria Regina Celestino de. Metamorfoses Indígenas: identidade e cultura nas aldeias coloniais do Rio de Janeiro. Rio de Janeiro: Arquivo Nacional, 2003.

ALMEIDA, Maria Regina Celestino de. Identidades étnicas e culturais: novas perspectivas para a história indígena. In: ABREU, Martha. SOILHET, Rachel. Ensino de História: Conceitos, temáticas e metodologia. 2 ed. Rio de Janeiro. Casa da Palavra, 2009, p. 27-37.

BAKHTIN, Mikhail. Marxismo e Filosofia da Linguagem (12. ed.) São Paulo. Editora: Hucitec, 2006.

CARDOSO, Oldimar. A Didática da História e o slogan da formação de cidadãos. São Paulo, Tese (Doutorado). Universidade de São Paulo, 2007.

CARVALHO JÚNIOR, Almir Diniz de. Índios Cristãos - A Conversão dos Gentios na Amazônia Portuguesa. São Paulo, Tese (Doutorado). Universidade Estadual de Campinas, 2005.

CARVALHO JÚNIOR, Almir Diniz de. Índios Cristãos na Amazônia Colonial. In: Luisa Tombini Wittman. (Org.). Ensino (d)e História Indígena. 1. ed. Belo Horizonte: Autêntica, 2015, v. 1, p. 47-79.

CARNEIRO DA CUNHA, Manuela (Org.). História dos Índios No Brasil (1. ed.). São Paulo: Companhia das Letras, 1992.

CHARTIER, Roger. História Cultural: entre práticas e representações. Lisboa: DIFEL, 1990.

COELHO, Mauro Cezar. As populações indígenas no livro didático, ou a construção de um agente histórico ausente. In: 30a Reunião da ANPED, 2007, Caxambu. ANPED: 30 anos de pesquisa e compromisso social. Rio de Janeiro: ANPED, 2007. v. 1. p. 174-174.

COELHO, Mauro Cezar. A história, o índio e o livro didático: apontamentos para uma reflexão sobre o saber histórico escolar. In: ROCHA, Helenice Aparecida Bastos; REZNIK, Luís; MAGALHÃES, Marcelo de Souza (org.). A história na escola: autores, livros e leituras. Rio de Janeiro: Ed. FGV, 2009. p. 263-280.

COELHO, Wilma de Nazaré Baía; COELHO, Mauro Cezar. Os conteúdos étnico-raciais na educação brasileira: práticas em curso. Educar em Revista, Curitiba, n. 47, p. 67-84, mar. 2013.

COELHO, Wilma de Nazaré Baía; COELHO, Mauro Cezar. O improviso em sala de aula. In: Wilma de Nazaré Baía; COELHO, Mauro Cezar. Raça, cor e diferença: a escola e a diversidade. (2. ed.) Belo Horizonte: Mazza Edições, 2010, p. 104-123.

COELHO, Wilma de Nazaré Baía; COELHO, Mauro Cezar. Por linhas tortas - a educação para a diversidade e a questão étnico-racial em escolas da Região Norte: entre virtudes e vícios. Revista da ABPN, 4 (8), 2012, p. 137155.

FARAGE, Nádia. As muralhas dos sertões: os povos indígenas no rio Branco e a colonização.(1a. ed.) Rio de Janeiro: Paz e Terra / ANPOCS, 1991.

FRAZÃO, Érika; RALEJO, Adriana. Narrativas do "outro" no currículo de História: uma reflexão a partir de livros didáticos. In Monteiro, A. M., Gabriel C.T., \&Araujo C.M. (Orgs.).Pesquisa em Ensino de História: entre desafios epistemológicos e apostas políticas. Rio de Janeiro, Mauad X: FAPERJ, 2014, p. 173-187.

FONSECA, Selva Guimarães. A nova LDB, os PCNs e o ensino de história. In: Didática e Prática do ensino de História. Campinas: Ed. Papirus, 2008, p. 29-38.

GARCIA, Elisa. As diversas formas de ser índio: políticas indígenas e políticas indigenistas no extremo sul da América portuguesa. Rio de Janeiro, Tese (Doutorado). Universidade Federal Fluminense, 2007.

GALIAN, Cláudia Valentina Assumpção. Os PCN e a elaboração de propostas curriculares no Brasil. Cadernos de Pesquisa, São Paulo, v. 44,n. 153,p. 648-669, set./2014.

GORDON, Cesar. Economia selvagem: ritual e mercadoria entre os índios Xikrin-Mebêngôkre. São Paulo: UNESP: ISA; Rio de Janeiro: NUTI, 2006. 
LE GOFF, Jacques e NORA, Pierre (dir.). História: novas abordagens. Rio de Janeiro: Francisco Alves, 1986; idem. História: novos objetos. Rio de Janeiro: Francisco Alves, 1988; História: novos problemas. Rio de Janeiro: Francisco Alves, 1984; BURKE, Peter. A escola dos Annales (1929-1989) - A Revolução Francesa da Historiografia. São Paulo: UNESP, 1997.

MIRANDA, Sonia Regina De; LUCA, Tânia Regina De. O livro didático de história hoje: um panorama a partir do PNLD. Revista Brasileira de História. São Paulo, v. 24, n. 48, 2004, p. 123-144.

MONTEIRO, John. Negros da Terra: Índios e Bandeirantes nas origens de São Paulo. 2. ed. São Paulo: Companhia das Letras, 1994.

ROLLER, Heather Flynn. Expedições coloniais de coleta e a busca por oportunidades no sertão amazônico, c. 1750-1800. Revista de História, São Paulo, nº 168, p. 201-243, Janeiro/Junho de 2013.

SANTOS, Wanderley Guilherme dos. Cidadania e Justiça: a política social na ordem brasileira. Rio de Janeiro: Campus, 1979.

SILVA, Maria de Fátima Barbosa da. Livro didático de História: representações do 'índio' e contribuições para a alteridade. Revista História Hoje, 1(2), 2012, p.151-168.

SILVA, Edson. O ensino de História Indígena: possibilidades, exigências e desafios com base na Lei 11.645/08. Revista História Hoje, 1(2), 2012, p. 213-223.

VAINFAS, Ronaldo. A heresia dos Índios: catolicismo e rebeldia no Brasil colonial. São Paulo: Companhia das letras, 1995.

VELASCO, Diego; BARCELLOS, Vitor. Demandas do tempo presente e sentidos de cidadania: redefinições e deslocamentos no currículo de História (Anos 1980 x Anos 2010). In: Monteiro, A. M., Gabriel C.T., \& Araujo C.M. (Orgs.), Pesquisa em Ensino de História: entre desafios epistemológicos e apostas políticas. Rio de Janeiro, Mauad X: FAPERJ, 2014, p. 261-274.

Submissão: 20/06/2017

Aceite: 07/09/2017 